paper. Particular thanks for the enthusiasm and dedication of the radiographers Sharron Cox, Jane Mattock, Marie Ayears Jackie Scrutton, and Alison Baker, and to my husband, John, for his unfailing support and encouragement.

1 Campbell S, Pearce JMF. The prenatal diagnosis of foetal strictural anomalics by ultrasound. Clin Obstet Gynaecol 1983;10:475-506.

2 Campbell S, Smith P. Routine screening for congenital anomalies by ultrasound. In: Rodeck CH, Nicolaides K. Prenatal diagnosis. London Royal College of Obstetricians and Gynaecologists; Chichester: Wiley, 1984:325-30.

$3 \mathrm{McNay}$ M. Clinical considerations in screening for foetal abnormalities. British Medical Society Ultrasound Bulletin. 1991;No 63:23.

4 Chitty LS, Hunt GH, Moore J, Lobb MO. Effectiveness of routin ultrasonography in detecting fetal structural abnormalities in a low risk population. BMF 1991;303:1165.

5 Royal College of Physicians. Report: prenatal diagnosis in genetic screening. London: RCP, 1989:14-5.

6 Thomson P. Where risks exist expectant mothers want tests. The Times 1991 Dec 2:15.

7 Royal College of Obstetricians and Gynaecologists. Working party report on routine ultrasound examination in pregnancy. London: RCOG, 1984:10.

8 Hecher K, Henning K, Spernol R, Szalay S. Spontaneous remission of urinary tract obstruction and ascites in a foetus with posterior urethral valves. Ultrasound in Obstetrics and Gynaecology. 1991;1:426-43.

9 Benacerraf BR, Adzick NS. Foetal diaphragmatic hernia; ultrasound diagnosi and clinical outcome. Am f Obstet Gynecol 1987;156:573-6.

10 Crawford DC, Chita SK, Allan LD. Prenatal diagnosis of congenital heart disease: factors affecting obstetric management and survival. Am f Obstet Gynecol 1988;159:352-6.

11 Hansman $M$. The foetus as a patient: the foetus as a person? Ultrasound in Obstetrics and Gynaecology 1991;1:305-6.

12 Chervenak FA, McLullogh LB. Ethics, an emerging subdiscipline of obstetric ultrasound, and its relevance to routine obstetric scanning. Ultrasound in Obstetrics and Gynaecologv 1991;1:18-20.

(Accepted 18 March 1992)

\title{
Toxicity of norpethidine in sickle cell crisis
}

\author{
B J Pryle, H Grech, P A Stoddart, R Carson, \\ T O'Mahoney, F Reynolds
}

Department of

Anaesthesia, St Thomas's

Hospital, London SE1 7EH

B J Pryle, lecturer

P A Stoddart, registrar

R Carson, laboratory scientific

officer

T O'Mahoney, research

assistant

F Reynolds, reader in

pharmacology applied to

anaesthesia

\section{Department of}

Haematology, St Thomas's Hospital, London SE1 7EH

$\mathrm{H}$ Grech, lecturer

Correspondence to:

Dr Reynolds.

BMf 1992;304:1478-9
Over six months we observed eight episodes of focal and generalised seizures in patients with sickle cell disease who had been treated with high doses of intramuscular pethidine. Recently Mitchell et al reported the death during grand mal seizure of a man in sickle cell crisis after two days of taking high dose pethidine. ${ }^{1}$ Norpethidine, an N-demethylated metabolite of pethidine, was identified as neurotoxic by Batterman in 1957, and subsequent studies have documented the adverse consequences of norpethidine accumulation..$^{23}$ Although isolated norpethidine concentrations have been measured at random in patients with sickle cell disease, we have found no systematic study. Our objective was to measure serum pethidine and norpethidine concentrations after multiple doses of pethidine to assess the extent of their accumulation and to identify their relation with seizures.

\section{Patients, methods, and results}

Fourteen AfroCaribbean patients with a diagnosis of sickle cell crisis who were receiving two hourly intramuscular pethidine gave verbal consent to give blood for analysis. Blood was taken immediately before and $15,30,60$, and 120 minutes after a pethidine injection. The patient's weight, serum urea and creatinine concentrations, most recent individual dose of pethidine, total dose in the previous 24 hours per kilogram body weight ( 24 hour pethidine dose), and total dose of pethidine during the crisis (total dose) were noted. Two additional patients who suffered grand ma seizures while receiving high dose pethidine treatment had blood samples taken shortly after the convulsions. Pethidine and norpethidine concentrations were measured by gas chromatography. ${ }^{4}$

Nine men and seven women of mean age 27 years (range 17-45) and mean weight $59 \mathrm{~kg}$ (range 50-70) were investigated. They had received two hourly intramuscular pethidine for between one and 35 days (mean seven, mode three). All except one had detectable concentrations of pethidine and norpethidine in the first sample. Mean (range) pharmacokinetic data for pethidine and norpethidine were: maximum measured plasma concentration $1.29(0.46-2 \cdot 8)$ and 0.72 $(0 \cdot 24-1 \cdot 86) \mu \mathrm{g} / \mathrm{ml}$; time to maximum concentration $37 \cdot 5(12-120)$ and $55(15-120) \mathrm{min}$; area under the curve of concentration against time curve 109 $(20 \cdot 5-243)$ and $66 \cdot 2(18-100) \mu \mathrm{g} . \mathrm{s} / \mathrm{ml}$. Maximum measured concentrations of norpethidine exceeded $1 \mu \mathrm{g} / \mathrm{ml}$ in four patients, three of whom had suffered a convulsion within a few hours of sampling. Two of these patients had been taking pethidine tablets at home before admission, and one had significant renal impairment (serum creatinine concentration $146 \mu \mathrm{mol} / 1$, normal range 50-100).

Linear regression analysis showed that the maximum measured concentration (figure) and area under the time concentration curve for norpethidine correlated significantly with the 24 hour pethidine dose $(r=0.74$, $\mathrm{p}=\mathbf{0 . 0 0 1}$ for both). The relation was also significant for pethidine $(r=0.56, \mathrm{p}<0.05$ for both $)$. There was no
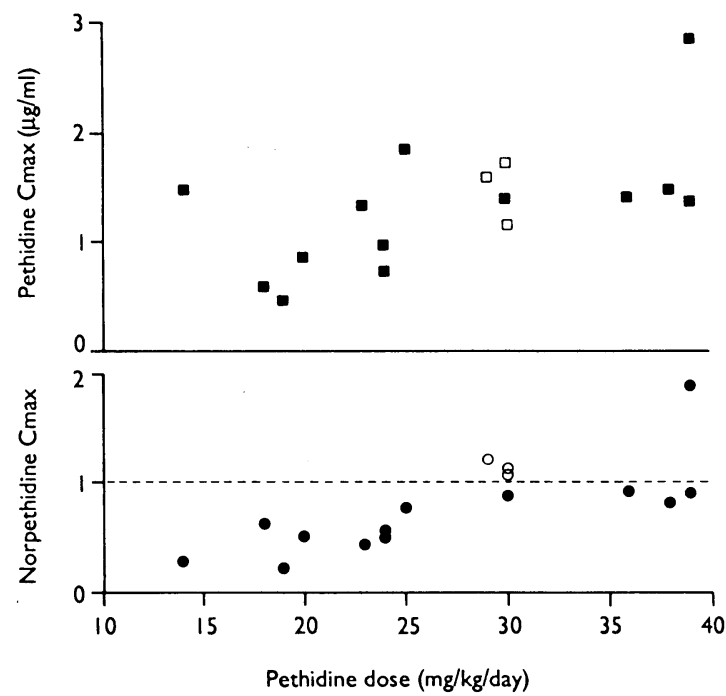

Maximum measured concentration of pethidine (square symbols) and norpethidine (round symbols) after intramuscular pethidine plotted against daily dose of pethidine in 16 patients. Open symbols represen the three patients who had convulsions

association between peak plasma pethidine concentration and seizures. There was no correlation between the total dose or last dose of pethidine and the maximum measured concentration or area under the time concentration curve for pethidine and norpethidine.

\section{Comment}

The results suggest that daily doses of pethidine greater than $25 \mathrm{mg} / \mathrm{kg}$ may be associated with toxicity (figure), particularly in the presence of renal impairment or if pethidine has been taken orally, when high first pass clearance results in rapid conversion to norpethidine. As the life expectancy of sickle cell patients increases, renal impairment becomes a more significant problem in older patients. The plasma half life of norpethidine with normal renal function is 14-20 hours, which implies that norpethidine concentrations may take about three days to reach $90 \%$ of the final plateau value. As all but one of our patients had been receiving pethidine for three days or more, no correla- 
tion between total pethidine dose and norpethidine concentration was found. In renal impairment norpethidine elimination is prolonged, leading to a greater accumulation.

Despite mounting evidence against pethidine as a first line analgesic in sickle cell crisis its use persists. We find that patients seem to prefer intramuscular pethidine despite its short duration of action and poor analgesia. This preference was also stated by patients' representatives (Sickle and Thalassaemia Association of Counsellors, Cardiff, September 1991). Apparent ease of administration and doctors' familiarity with the drug further perpetuates this legacy. Pethidine should not be used in patients who have a history of seizure after pethidine or renal impairment. ${ }^{23}$ Daily doses exceeding $25 \mathrm{mg} / \mathrm{kg}$ are likely to produce excitatory effects due to norpethidine toxicity.

1 Mitchell A, Fisher AP, Brunner M, Ware RG, Hanna M. Pethidine for painfu crisis in sickle cell disease. $B M \mathcal{F}$ 1991;303:249.

2 Kaiko RF, Foley KM, Grabinski PY, Heidrich G, Rogers AG, Inturrisi CE et al. Central nervous system excitatory effects of meperidine in cancer patients. Ann Neurol 1983;13:180-5.

3 Tang R, Shimomura SK, Rotblatt $M$. Meperidine-induced seizures in sickle cell patients. Hospital Formulary 1980;15:764-72.

4 Reynolds F, Beckett $\mathrm{AH}$. The determination of bupivacaine, lignocaine and mepivacaine in human blood. Br 7 Pharmacol 1968;20:704-6.

5 Szeto HH, Inturrisi CE, Houde R, Saal S, Cheigh J, Reidenberg MM. Accumulation of normeperidine, an active metabolite of meperidine, in patients with renal failure or cancer. Ann Intern Med 1977;86:738-41.

(Accepted 10 March 1992)

\section{Prevalence of potential pathogens in cervical canal before termination of pregnancy}

\section{Mike Cohn, Peter Stewart}

Department of Obstetrics and Gynaecology, Northern General Hospital, Sheffield S5 7AU Mike Cohn, research registrar Peter Stewart, consultant

Correspondence to: Dr M Cohn, Department of Obstetrics and Gynaecology, Leicester Royal Infirmary, Leicester LE1 5WW.

$B M \mathcal{F}$ 1992;304:1479 canal of women requesting terminations in Sheffield.

\section{Patients, methods, and results}

Pelvic infection is a complication of termination of pregnancy. ${ }^{1}$ The risk is increased if Chlamydia trachomatis or other potential pathogens are present in the cervical canal before the abortion. ${ }^{2}$ We report the prevalences of five potential pathogens in the cervical

We performed a retrospective analysis on the microbiological results of endocervical swabs taken from 1784 consecutive women requesting termination of pregnancy at this hospital. Neisseria gonorrhoeae was isolated from three women, $C$ trachomatis from 155 , Mycoplasma hominis from 315, Ureaplasma urealyticum from 340, and Trichomonas vaginalis from 30. One or more of these micro-organisms were isolated in 652 women.

For the analysis, if either $N$ gonorrhoeae or $C$ trachomatis was isolated the patient was deemed to be at a "high risk" of developing pelvic infection after termination whereas those harbouring $M$ hominis, $U$ urealyticum, or $T$ vaginalis were thought to be at "moderate risk." As marital status, age, and parity are likely to be related to risk a multivariate approach was taken. A cumulative logic model ${ }^{3}$ was fitted to the data with the SAS statistical package with the dependent variable as infection (none, moderate risk, high risk) and the explanatory variables as marital status (single, married, divorced, or separated), age ( $\leqslant 24,25-29$, $30-34, \geqslant 35$ ), and parity (primigravid, nulliparous other than primigravid, multiparous).

The model of best fit included all three of the explanatory variables; the fit became significantly poorer (at the $5 \%$ level) when any of these variables was dropped from the model. The final model showed that
Sensitivity ${ }^{\star}$ and efficiency† of selective testing for endocervical micro-organisms before termination of pregnancy

\begin{tabular}{|c|c|c|c|c|c|}
\hline \multirow[b]{2}{*}{ Patient characteristic } & \multirow{2}{*}{$\begin{array}{c}\text { No }(\%) \\
\text { women } \\
\text { tested }\end{array}$} & \multicolumn{2}{|c|}{ High risk infections } & \multicolumn{2}{|c|}{ All infections } \\
\hline & & Sensitivity (\%) & Efficiency (\%) & Sensitivity (\%) & Efficiency (\%) \\
\hline All women & $100 \cdot 0$ & $100 \cdot 0$ & $1 \cdot 00$ & $100 \cdot 0$ & $1 \cdot 00$ \\
\hline Single & $71 \cdot 1$ & $82 \cdot 8$ & $1 \cdot 16$ & $78 \cdot 8$ & $1 \cdot 11$ \\
\hline Multiparous & $43 \cdot 3$ & $39 \cdot 2$ & 0.90 & $40 \cdot 1$ & 0.92 \\
\hline Aged $<25$ years & $66 \cdot 2$ & $77 \cdot 7$ & $1 \cdot 17$ & $72 \cdot 1$ & 1.09 \\
\hline Single, multiparous & $16 \cdot 9$ & $21 \cdot 6$ & 1.28 & $20 \cdot 5$ & $1 \cdot 21$ \\
\hline Single, aged $<25$ years & $59 \cdot 7$ & $72 \cdot 6$ & $1 \cdot 22$ & $67 \cdot 3$ & $1 \cdot 12$ \\
\hline
\end{tabular}

$\star$ Sensitivity $=$ No detected/No infected $\times 100$. the chance of being at high risk of pelvic infection was increased for single women (adjusting for age and parity), those aged under 25 (adjusting for marital status and parity), and multiparous women (adjusting for marital status and age).

\section{Comment}

This large study showed that potential pathogens are found in the endocervical canal of an appreciable proportion of women requesting termination of pregnancy in Sheffield, thereby supporting the findings of other small studies in the United Kingdom. ${ }^{4}$ It also confirmed that such micro-organisms are more frequently isolated from young single women.

If $C$ trachomatis was present in the cervical canal before termination there was a $20-25 \%$ risk of the woman developing postabortion pelvic infection. ${ }^{2}$ This would have caused the woman discomfort and distress and might have required a further admission to hospital. A few of these women would experience long term subfertility and pelvic pain. ${ }^{5}$ Screening every patient requesting a termination would add about $£ 8.00$ to the cost of each abortion. However, the cost of treating women with established postabortion infection and of the long term sequelae should be set against this. Furthermore, by identifying infected women their partners can be tested and if necessary treated, thereby reducing the chances of the woman being reinfected and the pool of infected subjects within the population.

As cervical infections are more common in certain groups it would be possible to introduce selective screening to reduce the costs. The table illustrates the sensitivity and efficiency of different policies. If all single women under the age of 25 were tested only $60 \%$ of the population would be screened but $73 \%$ of infected subjects would be detected. Furthermore, most patients for whom subsequent fertility is most important would be screened.

We recommend that all patients requesting termination of pregnancy are screened for potential endocervical pathogens and that when these are detected appropriate antibiotics are prescribed at the time of the abortion. If resources are limited a selective policy could be introduced.

\section{We thank Carol Jaeger for statistical advice.}

\footnotetext{
Frank PI, Kay CR, Wingrave SV, Lewis TL, Osborne J, Newell C. Induced abortions and their early sequelae. $\mathcal{F} R$ Coll Gen Pract 1985;35:175-80.

Qvigstad E, Skaug K, Jerve F, Fylling P, Ulstrup JC. Pelvic inflammatory disease associated with Chlamydia trachomatis infection after therapeutic abortion. A prospective study. British foumal of Venereal Diseases 1983;59. 189-92.

3 Agresti A. Categorical data analysis. Chichester: Wiley, 1990:332-6.

4 Ridgway GL, Mumtaz G, Stephens RA, Oriel JD. Therapeutic abortion and chlamydial infection. BMF 1983;286:1478-9.

Heisterberg L. Pelvic inflammatory disease following induced first-trimester
} abortion. Dan Med Bull 1988;35:64-75. 